\title{
A ressurreição de Jesus Uma abordagem a partir da reflexão de Walter Kasper ${ }^{1}$
}

\author{
The resurrection of Jesus \\ An approach from the reflection of Walter Kasper
}

Angela Cristina Germine Pinto Caldeira

\section{Resumo}

A páscoa é um conjunto de acontecimentos situados na história, de uma comunidade que se define em relação ao que aconteceu a Jesus, a ressurreição. No Novo Testamento a ressurreição de Jesus é profissão de fé e testemunho dos crentes, acontecimento da palavra e da linguagem da fé cristã. Trata-se de um acontecimento que transcende o âmbito histórico, pois o Ressuscitado é realidade atual por seu Espírito na história. A ressurreição de Jesus Cristo com seu caráter escatológico e universal para a humanidade desperta a necessidade de interpretá-la. Vários teólogos contribuíram com sua interpretação, buscando através de enfoques hermenêuticos distintos, e mais adequados aos conceitos e representações humanas, explicitar este acontecimento extraordinário. Pela reflexão de Walter Kasper na ressurreição de Jesus se iniciou a ação escatológica de Deus, a exaltação de Jesus e a salvação cristã.

\footnotetext{
${ }^{1}$ Kasper é teólogo, dedicado em particular à causa do ecumenismo. Foi Bispo na Alemanha (Rottenburg-Stuttgart), e trabalhou muitos anos no Pontifício Conselho para a Unidade dos Cristãos em Roma. Em 21 de fevereiro de 2001 foi elevado a cardeal, com o título de cardeal-diácono de Ognissanti in Via Appia Nuova. Em 2011, o Papa Bento XVI o elevou de cardeal-diácono à ordem de cardeal-presbítero. Disponível em: $<$ http://pt.wikipedia.org/wiki/Walter_Kasper $>$. Acessado em 3 de maio de 2013.
} 
Palavras-chave: Cristologia; W. Kasper; Novo Testamento; Ressurreição.

\begin{abstract}
Easter is a set of events in the history of a community that defines itself in relation to what happened to Jesus, the resurrection. In the New Testament the resurrection of Jesus is the profession of faith and witness of believers, of the word and the language of the Christian faith. This is an event that transcends the historical context, as the risen one is current reality by his spirit in the history. The resurrection of Jesus Christ with his eschatological and universal character for the humanity awakens the need to interpret it. Several theologians contributed their interpretation, seeking through approaches best suited to the concepts and human representations, clarify this extraordinary event. In reflection of Walter Kasper in the resurrection of Jesus began the eschatological action of God, the exaltation of Jesus and Christian salvation.
\end{abstract}

Keywords: Christhology; W. Kasper; New Testament; Resurrection.

\title{
Introdução
}

A problemática em torno da ressurreição de Jesus se encontra no fato de ser um acontecimento que não possui um testemunho neotestamentário que afirme tê-la presenciado, embora tenha sido interpretada como ação divina salvífica. O tipo de morte violenta e vergonhosa de Jesus contrasta com o entusiasmo dos discípulos ao anunciarem Jesus como o Messias: "Deus, em seu desígnio e previsão, determinou que Jesus fosse entregue pelas mãos dos ímpios, e vós o matastes, pregando-o numa cruz. Mas Deus o ressuscitou, libertando-o das angústias da morte porque não era possível que ela o dominasse" (At 2,23-24).

$\mathrm{O}$ evento da ressurreição funda a unidade entre o Jesus pré pascal e o Cristo pós pascal. O Novo Testamento fala de um modo novo sobre a existência terrestre de Jesus. Ele se torna o centro e a norma de toda a fé posterior. A ressurreição de Jesus é o fundamento da confissão cristológica.

Refletir sobre a ressurreição de Jesus, elencar seus principais elementos e abrir o diálogo teológico sobre o tema contribui para explicitar seu mistério. A presente comunicação resultou do Seminário de Questões Especiais de Método Teológico ministrado pelo Professor Doutor Dom Paulo Cezar Costa. Ao estu- 
darmos teólogos que contribuíram para modelar a teologia contemporânea verificou-se a riqueza e a diversidade que os caracterizaram. Procuramos discernir suas originalidades e situá-los no desenvolvimento do pensamento teológico de acordo com a opção que adotaram para manifestar suas convicções.

O método histórico-crítico marcou o estudo bíblico no século XX. Com a intenção de melhor compreender a Escritura Sagrada o método foi usado como instrumento, privilegiando o sentido original e a história da redação. A fragmentação dos textos e uma grande multiplicidade de hipóteses acarretaram um forte descrédito acerca desse método. O Concílio Vaticano II estabeleceu bases para que a reflexão teológica não prescinda do apoio escriturístico.

A comunicação que faremos a seguir proporcionará uma visão sumária da reflexão de Walter Kasper sobre a ressurreição de Jesus. A reflexão do autor se insere na renovação de perspectivas teológicas que se seguiram ao Vaticano II. Reuniu elementos da tradição, hermenêuticos e teológicos para fundamentar a sua perspectiva sobre a ressurreição de Jesus. Para o autor, na ressurreição de Jesus se iniciou a ação escatológica de Deus, a exaltação de Jesus e a salvação cristã.

\section{Os fundamentos da fé na ressurreição de Jesus}

\subsection{Dados da Tradição}

O autor observa que a morte de Jesus na cruz representou um fim para seus discípulos e um descrédito religioso. Para uma nova retomada seria preciso algo intenso que superasse o evento da cruz. Para o autor a ressurreição de Jesus é a resposta. Segundo o testemunho de todos os livros bíblicos, os discípulos anunciaram depois da morte de Jesus que Deus o havia ressuscitado, e que ele, antes crucificado, havia aparecido vivo e os enviado para anunciar sua mensagem a todo mundo (At 2,32-33). Estes testemunhos são a base e o centro da mensagem neotestamentária: "E se Cristo não ressuscitou, a nossa pregação é sem fundamento, e sem fundamento também é nossa fé" (1Cor 15,14).

Relatos de incredulidade, dúvidas e medo dos discípulos falam a favor dos testemunhos neotestamentários, que narram elementos históricos com finalidade catequética, querigmática, ou contendo elementos que começavam surgir. A força maior dos testemunhos é o fato de que estavam decididos a morrer por sua mensagem (Mc 16,14; Mt 28,17; Lc 24,11; Jo 20,24-29). 
Em primeiro lugar, Kasper se interessa pela transmissão da mensagem da ressurreição. Enquanto o testemunho da paixão de Jesus segue um esquema comum nos quatro Evangelhos, os testemunhos pascais se diferenciam notavelmente divididos entre o querigma pascal e as histórias pascais. O querigma pascal aparece em fórmulas de fé das primeiras comunidades ligadas à morte e à ressurreição de Jesus. A mais antiga confissão é a de 1Cor 15,3-5. Outros textos semelhantes (pré paulinos) que não falam das aparições, testemunham a ressurreição de Jesus (Rm 1,3, e Fl 2,6-11). As histórias pascais são extensas (Lc 24,13-43; Jo 20,19-29), nelas se fala de encontros com o Ressuscitado e do sepulcro vazio.

Com relação ao sepulcro vazio, apesar de todos os evangelistas atestarem sua realidade, Kasper explica que as referências ao sepulcro apresentam problemas. Segundo a mentalidade e a antropologia judaica, seria impossível falar de ressurreição sem o sepulcro, mas a constatação de um núcleo histórico nos relatos do sepulcro não prova a ressurreição de Jesus. A realidade do sepulcro vazio representa um canal de união entre o crucificado e as aparições. Para Kasper o sepulcro vazio tem a intenção de anunciar a ressurreição, é um sinal e não uma prova da ressurreição de Jesus.

As tradições do querigma e das histórias pascais, provavelmente unidas por Marcos, apesar de divergências concordam que Jesus apareceu depois de sua morte a determinados discípulos, se mostrou vivo e foi anunciado como Ressuscitado entre os mortos. Portanto, Kasper destaca que para a Igreja primitiva foi importante os testemunhos com caráter de confissão de fé dos encontros com o Ressuscitado. Assim, segundo Kasper, deve-se partir inicialmente das confissões de fé pascais e das tradições referentes às aparições.

$\mathrm{O}$ autor menciona divergências entre a tradição querigmática e as narrações pascais, mas apesar das diferenças destaca que todas as tradições giram em torno de um mesmo núcleo. A ressurreição não é narrada ou descrita e, portanto, não há um só testemunho neotestamentário que tenha presenciado a ressurreição de Jesus. A realidade da ressurreição é inseparável de seu testemunho. Kasper explica que a ressurreição não é um fato do passado, mas é uma realidade sempre atual para as testemunhas. O importante é a credibilidade existencial que prestam à fé as testemunhas da ressurreição mediante sua vida e sua morte ${ }^{2}$.

${ }^{2}$ KASPER, W. Jesus, El Cristo. Salamanca: Ediciones Sigueme, 1986.p.159. 


\subsection{Pressupostos hermenêuticos}

Para Kasper a ressurreição de Jesus fala de um acontecimento que transcende o histórico, portanto para falar sobre ela, de modo teologicamente responsável, são necessários pressupostos hermenêuticos fundamentais sobre o seu reconhecimento e como uma dimensão meta histórica pode se encaixar no âmbito do historicamente constatável.

O autor explica que a teologia clássica se descuidou da discussão hermenêutica dos testemunhos da ressurreição. Limitou-se a repetir os testemunhos de fé sem refletir sobre eles e sobre como ocorreu à ressurreição. Esta situação mudou com a teologia crítica moderna. Nela os pontos de vista histórico-exegéticos estiveram influenciados por pressupostos científicos, filosóficos e hermenêuticos. As investigações históricas percorreram um longo caminho até Bultmann, assimilando a filosofia existencial de Heidegger. A ele não interessava explicar o fato, mas compreender o fenômeno da fé na ressurreição. Por isso sua tese central era de que a ressurreição é a fé na cruz como acontecimento salvífico. E concluiu que o sentido da fé pascal é crer em Cristo presente no querigma. Pressupondo esta tese, todas as questões relacionadas às provas históricas perdem o sentido. Por isso recebeu a crítica não só de teólogos católicos, mas também de Barth, Kasmann e outros.

Pannenberg introduziu uma nova fase com sua interpretação da revelação como história. Kasper esclarece que sua atenção demasiada à investigação histórica foi criticada, entretanto situou a historicidade da ressurreição num horizonte hermenêutico mais amplo, ao considerar a independência entre fato e significado, apontando uma solução além do fato histórico em si e da redução a mera significação para a fé̉.

Outro passo, destacado pelo autor, na tentativa de solução para a relação conflitiva entre hermenêutica e história foi dado pelo Concílio Vaticano II. Em sua Constituição Dogmática Dei Verbum, n², a respeito da revelação busca na categoria de sinal um contexto mais amplo para tornar claros acontecimentos históricos: "Este plano de revelação se concretiza através de acontecimentos e palavras intimamente conexas entre si, de forma que as obras realizadas por Deus na história da salvação manifestam e corroboram os ensinamentos e as realidades significadas pelas palavras" ${ }^{4}$. Este esclarecimento

\footnotetext{
${ }^{3}$ Cf. KASPER, W. Jesus, El Cristo, p.160.

${ }^{4}$ Concílio Ecumênico do Vaticano II. Constituição pastoral sobre a igreja no mundo de hoje, Gaudium et Spes n 2. In: KLOPPENBURG, B; VIER, F. Compêndio Vaticano II. Petrópolis: Vozes, 1998.
} 
fundamental sobre a relação entre hermenêutica e história coloca a questão sobre o horizonte hermenêutico mais adequado. E, questões antropológicas também passaram a ser consideradas pelo enfoque teológico, pois a revelação só é possível à base de conceitos e representações humanas. Dessa forma o caráter insuperável e universal de Jesus é verificado de forma sempre nova. Sobrevindo novos graus de compreensão, novos horizontes e contextos, seu significado é expresso de modo novo e diferente.

Para Kasper, os testemunhos sobre a ressurreição falam de um acontecimento que transcende o âmbito histórico e não pode ser explicado dentro da história, somente do ponto de vista escatológico. Sinais ambíguos se tornam claros graças a uma antecipação crente do fim da história. Neste amplo horizonte se entendem os testemunhos da Igreja primitiva, e da tradição eclesiástica posterior ${ }^{5}$.

\subsection{Fundamentação teológica}

Inicialmente Kasper observa que os primeiros testemunhos da ressurreição se apóiam em aparições do Ressuscitado. A fórmula de fé de 1 Cor 15,3-5 fala de uma aparição a Pedro e outra aos Doze. Depois, a mais de quinhentos irmãos, a Tiago e a todos os apóstolos. Deste texto se pode concluir que as aparições do Ressuscitado têm a finalidade de legitimar certas autoridades da Igreja. Trata-se de fórmulas de legitimação. As aparições fundamentam sempre o apostolado, incluindo o motivo da missão. Entretanto, o autor ressalta que interpretar as aparições pascais de modo funcional esconde uma interpretação pessoal referente à pessoa de Cristo.

Em sua detalhada investigação da terminologia usada pelo Novo Testamento, o autor aponta que o termo chave usado é o verbo "aparecer" (1Cor 15,3-8; Lc 24,34; At 9,7; 13,31; 26,16), que se pode traduzir de três maneiras: "apareceu" aos discípulos; "foi revelado" como ação de Deus; e, como ação do próprio Cristo, "se deixou ver". Como o verbo aparecer foi usado pelo Antigo Testamento para designar teofanias (Gn 12,7; 35,9) as aparições do Ressuscitado se apresentam conforme o modelo teofânico, e como tais, revelações de Deus. Deus se revela como Deus oculto. O autor explica que o verbo "aparecer" sempre se encontra na forma "foi ressuscitado" o que significa que os discípulos viram o Senhor Ressuscitado, ou seja, uma

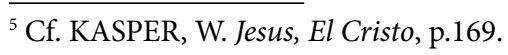


antecipação escatológica e definitiva de Deus (Gal 1,15; 2 Cor 4,6). Segundo Kasper, Deus é quem revela e o que revela é sua própria glória. E a revela no rosto do Jesus Cristo. O ser de Deus se manifesta quando Deus se identifica com o crucificado e o ressuscita da morte para vida ${ }^{6}$.

Um resultado parecido se chega pela análise das aparições nos Evangelhos nos quais o Ressuscitado sai ao encontro dos discípulos impondo sua presença, saudando, falando, consolando e enviando os discípulos sempre em nome de Deus. Em Mt 28,16-20 se encontra, segundo o autor, a melhor descrição onde se vislumbra algo da exousia divina. E nos textos em que se fala de tocar o Ressuscitado (Lc 24,39; Jo 20,26), inaceitáveis do ponto de vista teológico, possuem a finalidade de legitimar a identidade do Ressuscitado com o crucificado, ressaltar a corporeidade da ressurreição e evitar o espiritualismo ${ }^{7}$.

Kasper chama a atenção de que as aparições nãorepresentam acontecimentos objetivos. Nelas Jesus ganha autoridade e reconhecimento na fé dos discípulos. Tratou-se de uma experiência de fé, mas foram encontros com o Cristo presente no Espírito. A realidade do Ressuscitado fundamentou a fé. O encontro com o Senhor Ressuscitado se qualifica como encontro e experiência de Deus. Os discípulos viram a realidade do Reino de Deus chegando definitivamente em Jesus Cristo mediante sua morte, e perceberam a glória de Deus no rosto do crucificado. As aparições são a autorevelação escatológica de Deus.

\section{A perspectiva de W. Kasper sobre a ressurreição de Jesus}

\subsection{A ressurreição como ação escatológica de Deus}

Kasper observa que na Escritura existem duas formas de falar sobre a ressurreição de Jesus: emprega o verbo "ressuscitar" na forma ativa e passiva; e, "levantar" na forma transitiva e intransitiva. Essa forma figurada de falar corresponde à mentalidade judaica e ao helenismo da época. Ocasiona compreender por ressurreição tanto a dos mortos para a vida terrena, como a ressurreição escatológica dos mortos. A esperança no judaísmo tardio referente à ressurreição dos mortos no final dos tempos tem origem na fé em Yahweh como senhor da vida e da morte (1Sm 2,6; Dt 32,39).

\footnotetext{
${ }^{6}$ Cf. KASPER, W. Jesus, El Cristo, p. 172.

${ }^{7}$ Cf. Ibid., p.172.
} 
No Novo Testamento a ressurreição de Jesus significa que se iniciaram os acontecimentos escatológicos. Jesus é o primeiro dos ressuscitados (At 26,23; 1 Cor 15,20; Col 1,18). A ressurreição de Jesus se situa no horizonte de esperança escatológica e se qualifica como sucesso escatológico. A ressurreição é o começo de uma nova criação (1 Cor 15,42$)^{8}$. Portanto, não é difícil reconhecer uma relação entre a mentalidade do judaísmo tardio e como o Novo Testamento apresenta a ressurreição. Nesse sentido, o Novo Testamento na maioria das vezes atribuiu a obra da ressurreição de Jesus diretamente a Deus ( $\operatorname{Rm} 4,17$; 2Cor 1,9$)$.

O Novo Testamento raramente fala da ressurreição de Jesus na forma ativa (1Tess 4,14; Lc 24,7; Jo 20,9). A fórmula "Deus ressuscitou Jesus entre os mortos" prevalece e se converte em predicado divino (Rm 4,24; 2 Cor 4,14; Gal 1,1; Ef 1,20; Col 2,12). Portanto, a ressurreição de Jesus representa a decisiva ação escatológica de Deus. Revela quem é Deus, aquele cujo poder responde pela vida e pela morte, aquele que é amor e fidelidade, poder de vida nova diante da fraqueza humana. A ressurreição de Jesus é revelação e realização do Reino de Deus, anunciado por Jesus. Nela, Deus manifestou sua fidelidade ao amor e se identificou definitivamente com Jesus e sua causa9

Kasper explica que a fé na ressurreição de Jesus é a explicitação da fé mais fundamental que é a fé na possibilidade criadora e na fidelidade de Deus. Crer em Deus enquanto Deus, superior a tudo no mundo. A fé pascal significa confiar neste Deus que dispõe de possibilidades que vão além da morte. Um Deus que se revela de modo definitivo na ressurreição de Jesus. Trata-se do pleno alcance da fé cristã. Uma fé decidida a contemplar a realidade a partir de Deus, confiar em Deus na vida e na morte. Assim, o conceito cristão de Deus é inseparável da fé na ressurreição. A fé pascal é o resumo e a essência da fé cristã ${ }^{10}$.

\subsection{A ressurreição como exaltação}

Kasper acentua que a ressurreição é a confirmação definitiva da pessoa e da causa de Jesus. Para a exposição do que constitui a dimensão da ressurreição, Kasper analisa a profissão de fé 1 Cor 15,3-5. A uma proposição histórica se atribui um significado escatológico como cumprimento da promessa

\footnotetext{
${ }^{8}$ Cf. Ibid., p.176.

${ }^{9}$ Cf. Ibid., p. 177.

${ }^{10}$ Cf. KASPER, W. Jesus, El Cristo, p.177.
} 
veterotestamentária. Da relação entre as estrofes de 1Cor 15,3-5 se deduz que o significado salvífico da ressurreição, acentuando que Deus interveio efetivamente em um acontecimento histórico. A ressurreição tem seu término histórico em Jesus de Nazaré, crucificado e enterrado. A continuidade e a identidade entre o crucificado e o Ressuscitado se baseiam na fidelidade de Deus à criação e à aliança. A ressurreição de Jesus significa que o novo eón irrompeu na história ${ }^{11}$.

Para a dimensão teológica da ressurreição Kasper destaca a utilização dos termos "exaltar" e "exaltação". No hino cristológico da Carta aos Filipenses, e em outros textos do Novo Testamento, se fala de exaltação em vez de ressurreição (Lc 24,26; Ef 4,8; Tm 3,16; Hb 12,2). Em outros textos a exaltação é conseqüência da ressurreição. Em Mt 28,16, o Exaltado é dotado de poder divino. E, de modo claro, a relação entre cruz, ressurreição, exaltação e envio do Espírito aparece no Evangelho de João. Em João exaltação significa tanto ser levantado na cruz, como exaltação ao Pai (Jo 3,14; 8,28; 12,32) e glorificação (Jo 7,39). A obediência até a cruz é o centro mais íntimo da existência de Jesus, e a entrega ao Pai é ao mesmo tempo entrada na glória eterna (Jo 17,5. 23). O Exaltado na cruz e ao Pai em um único acontecimento assume todo poder (Jo 12,32). Por isso, o Ressuscitado doa seu Espírito aos discípulos fazendo-os partícipes de seu poder pleno (Jo 20,22). Morrendo, Jesus se entrega na cruz em obediência à vontade do Pai; este a aceita de modo que a auto-entrega de Jesus alcança sua meta e significa sua exaltação ${ }^{12}$.

Com exceção de Lucas, os textos do Novo Testamento unem ressurreição e exaltação. Lucas intercala um tempo de quarenta dias entre a ressurreição e a exaltação de Jesus querendo expressar uma continuidade entre Jesus e a Igreja. A ascensão é a última aparição pascal, e ao mesmo tempo o início da Igreja.

Kasper explica que a exaltação era também considerada no judaísmo tardio. A idéia do justo arrebatado ao céu indicava sua importância escatológica. As proposições mais antigas sobre a exaltação de Jesus se encontram em um contexto escatológico (1Ts 1,$10 ; \mathrm{Hb} 3,20)$. A exaltação de Jesus significa que no Ressuscitado se decide o destino escatológico. Enquanto Exaltado, Jesus participa do poder divino e da glória de Deus ( $\mathrm{Rm} \mathrm{1,3).} \mathrm{O} \mathrm{autor} \mathrm{acentua}$ um segundo aspecto que a partir da idéia de exaltação vai se desenvolvendo. Se a profissão de fé em Jesus Cristo é tão decisiva, seu senhorio é considerado também na vida presente. Exaltação significa entronização celeste, revesti-

\footnotetext{
${ }^{11}$ Cf. Ibid., p.179.

${ }^{12}$ Cf. Ibid., p.180.
} 
mento de dignidade e poder divino. E neste sentido, dotado de poder, Jesus intercede por nós ao Pai $(\mathrm{Rm} 8,34)$ e nos protege do juízo de Deus $(\mathrm{Rm} 6,9)$. Jesus é nosso intercessor $(\mathrm{Hb} 7,25)^{13}$.

A ressurreição de Jesus é a unidade íntima de um acontecimento histórico e escatológico. A dimensão histórica da ressurreição de Jesus consiste no que aconteceu a Jesus de Nazaré, o crucificado. Na ressurreição, o que humanamente representa o fim é, ao mesmo tempo, a vontade de Deus, um novo começo e razão de esperança. Significa que a obediência de Jesus representou o que mais profundo ocorreu na sua morte: a entrega a Deus e a aceitação desta entrega, ou seja, Deus encontra a acolhida definitiva no homem e este em Deus. Com esta interpretação aparece a questão da corporeidade da ressurreição. Kasper adverte que negar a corporeidade da ressurreição é cair no docetismo, e explica que a corporeidade da ressurreição se baseia na Escritura e que esta corresponde à perspectiva moderna.

Para o povo hebreu o corpo é criação de Deus, refere-se ao homem inteiro, e não apenas uma parte. $\mathrm{O}$ corpo é a possibilidade e a realidade da comunicação com Deus e com os demais homens. Na perspectiva de S. Paulo o corpo será sárquico ou pneumático. O corpo pneumático (1 Cor 15) dedicado à ressurreição é um corpo soma pneumatikón, ou seja, um corpo qualificado e determinado pelo Espírito de Deus. Por isso, S. Paulo fala em servir e glorificar a Deus com o corpo $(\mathrm{Rm} 12,1$; 1Cor 6,20$)$. O pneuma não é a matéria, é a dimensão em que o corpo se acha, se está na dimensão de Deus.

A corporeidade da ressurreição significa que o homem inteiro se encontra na dimensão de Deus. Na antropologia moderna, a corporeidade se refere à relação do homem com o mundo. O corpo é ao mesmo tempo um meio que vincula o homem ao mundo, pois o homem não vive sem estar no mundo e é impossível uma existência separada do corpo. Através do corpo, o homem estabelece relações que se podem qualificar de diversas maneiras.

Jesus entrou na dimensão de Deus por sua ressurreição e exaltação, e se encontra até a consumação do mundo de uma maneira nova e divina. Essa maneira nova, explica Kasper, corresponde ao chamado "céu", um lugar superior sobre a terra. Teologicamente "céu" é a dimensão que a criatura alcança em Deus. Este "céu" se constituiu no momento que a primeira criatura chegou a Deus de modo escatológico e definitivo. O céu é o corpo pneumático de Cristo. No corpo de Cristo exaltado culmina toda a realidade. Por isso, é

${ }^{13}$ Cf. Ibid., p.183. 
consequente chamar a Igreja de Corpo de Cristo, enquanto é o lugar em que Cristo está presente pela fé, esperança e amor ${ }^{14}$.

A importância histórica salvífica que Jesus adquire em sua ressurreição e exaltação é expressa na Escritura mediante a confissão de fé em Cristo, como Kyrios. Da profissão de fé, "Jesus é o Cristo", se chegou à profissão decisiva de "Jesus é o Senhor" (Rm 10,9; 1Cor 12,3; Fl 2,11). Com esse título se expressa o poder celeste do Ressuscitado e Exaltado. Como explica Kasper, Paulo chama Kyrios ao Senhor presente e Exaltado (2Cor 3,17). Isto significa que para Paulo, Jesus Cristo está Exaltado e também presente por seu pneuma na Igreja, pela palavra e sacramento. Seu senhorio se estende também a todo o cosmos e retrocede ao início da criação (1 Cor 8,6; Ef 1.10; Col 1,15-20; Jo 1,1-10). Todo o universo está submetido a Cristo. Ele é o mesmo tempo o lugar do Reino de Deus. E nele, e por Ele, se estabelece o Reino de Deus ${ }^{15}$. Esta explicação cosmológica e protológica da soberania do Senhor é uma conseqüência do caráter escatológico da vida, morte e ressurreição de Jesus. Nele irrompeu o final e a consumação da história, e se alcançou a meta em que tudo alcança a plenitude. E se com ele chegamos à salvação isso se deve ao fato de que tudo foi criado desde o princípio em Cristo. $\mathrm{O}$ sim do Pai à Cristo e à sua obra é ao mesmo tempo sim a toda realidade e à salvação do mundo ${ }^{16}$.

\subsection{A ressurreição como acontecimento salvador}

Kasper apresenta a ressurreição como evento de salvação. Para o Novo Testamento a ressurreição de Jesus e sua entronização no poder divino são o início e a antecipação da ressurreição dos mortos. Segundo Paulo, "se não há ressurreição dos mortos, então Cristo não ressuscitou" (1 Cor 15,13). Isso quer dizer que a ressurreição de Jesus se encontra numa perspectiva universal, é um acontecimento incomparável e aberto ao futuro, implica a consumação escatológica do homem em sua totalidade, uma nova humanidade e um mundo novo ${ }^{17}$.

A ressurreição de Jesus representou uma correção do horizonte escatológico apocalíptico do judaísmo tardio. Para o Novo Testamento não se trata de um futuro qualquer, mas a expansão universal do que irrompeu na pessoa e destino de Jesus. O futuro de toda a realidade se encontra decisivamente

\footnotetext{
${ }^{14}$ Cf. KASPER, W. Jesus, El Cristo, p.186.

${ }^{15}$ Cf. Ibid., p. 188.

${ }^{16}$ Cf. Ibid., p.189.

${ }^{17}$ Cf. Ibid., p.189.
} 
determinado por Ele e graças a sua ressurreição se converteu em salvação do mundo $(\mathrm{Rm} 4,25)$.

A confirmação definitiva de Jesus e sua incorporação à comunhão de vida e amor com Deus foi por sua ressurreição. Deus aceitou o ser de Jesus para os outros e se reconciliou definitivamente com o mundo. Nele e por Ele, Deus se encontra irrevogavelmente voltado para todos os homens. A ressurreição e exaltação de Jesus descortinam uma existência nova que abraça o presente e o futuro através da liberdade e da esperança ${ }^{18}$.

Kasper observa a necessidade de dissociar a esperança cristã de utopias modernas e ideológicas. A esperança pascal coloca o cristão no caminho da cruz, ou seja, na obediência diária realizada com o corpo $(\operatorname{Rm~} 12,1){ }^{19}$. Se funda na fidelidade de Deus à sua criação e aliança. Baseia-se no amor de Deus que apareceu de modo escatológico definitivo na morte e ressurreição de Jesus e a esse amor pertence todo o futuro (Ef 2,6; Col 3,10).

A realidade escatológica e definitiva que irrompeu em Cristo diz respeito à situação objetiva de todos os homens e a possibilidade de introduzirem-se numa nova realidade pela fé e pelo batismo. Na medida em que Jesus Cristo pertence objetiva e ontologicamente à situação de cada homem, a ressurreição representa um poder existencial que qualifica a nova criatura (2Cor 5,17; Gal 20,20. 6,15). Este nova criatura se caracteriza principalmente pela liberdade que se baseia em Jesus Cristo. Liberdade em favor dos irmãos (1Cor 6,12; $10,23)$, e que se concretiza em recusa ao pecado (Rm 6,18-23; Jo 8,31-36), à morte $(\operatorname{Rm} 6,23)$ e à lei $(\mathrm{Rm} 7,6-8)^{20}$.

A presença salvadora de Jesus entre os discípulos fundamenta não só a esperança e a liberdade, mas uma nova postura dos discípulos em torno do Senhor. A comunhão de mesa interrompida pela morte é resgatada pelo Ressuscitado. O Ressuscitado volta a se reunir com seus discípulos na comunhão de mesa interrompida por sua morte. Por isso, a Eucaristia junto com a Palavra é o lugar genuíno de encontro com o Ressuscitado. A nova comunhão é ao mesmo tempo sinal de perdão. A ressurreição de Jesus fundamenta o perdão dos pecados e a concessão do shalom escatológico. Eucaristia e penitência estão, portanto, implicadas na ressurreição e nas aparições do Ressuscitado (Jo 20,23). Elas são a expressão, e o sinal, da nova presença salvífica de

\footnotetext{
${ }^{18}$ Cf. Ibid., p.190.

${ }^{19}$ Cf. Ibid., p.191.

${ }^{20}$ Cf. KASPER, W. Jesus, El Cristo, p.190.
} 
Jesus com os seus ${ }^{21}$. Neste sentido a Igreja é um fenômeno escatológico que com todo seu caráter histórico participa do caráter escatológico definitivo da nova história, que se iniciou na ressurreição. Kasper chama a atenção que só é Igreja de Cristo se essa Igreja mantém a fé na cruz e na ressurreição de Jesus. $\mathrm{Na}$ verdade de Cristo e na Igreja está prometido ao mundo de modo irrevogável por Jesus Cristo a verdade salvadora de Deus ${ }^{22}$.

\section{Conclusão}

Pelos textos bíblicos se constata que a ressurreição jamais foi descrita, mas todas as tradições neotestamentárias concordam que Jesus apareceu depois de sua morte a determinados discípulos, se mostrou vivo e foi anunciado como Ressuscitado entre os mortos.

Kasper destaca a importância da credibilidade existencial que os testemunhos da ressurreição fornecem à fé, e transcendem o âmbito do historicamente constatável. A fé pascal se fundamenta sobre o testemunho dos apóstolos transmitido pela Igreja como comunidade de crentes e por este testemunho o Ressuscitado é realidade atual por seu Espírito na história. A fé na ressurreição se justifica por ser uma ação de Deus. $\mathrm{O}$ universo inteiro é submetido a Cristo Exaltado. A profissão de fé em Cristo como Kyrios, se estende a todo o cosmo e retroage à criação. E, se Nele irrompeu o final e a consumação da história, com Ele chega a salvação.

Desde o Concílio Vaticano II a reflexão sobre Cristo ocupa um lugar cada vez maior. Tal constatação se impôs a autores da teologia contemporânea como K. Rahner, H. Von Balthasar e J. Moltmann, entre outros. Uma concentração cristológica apareceu com clareza, entretanto distante de uma uniformização, resultou em uma multiplicidade de cristologias. Walter Kasper se situa entre os teólogos que respondem à tarefa imposta pelo Vaticano II de renovar a Igreja. Esta tarefa, segundo ele, não poderia ser enfrentada exclusivamente no nível da eclesiologia. Era preciso uma reflexão aprofundada sobre o verdadeiro fundamento e sentido da Igreja e este sentido se resume em uma confissão de fé: Jesus é o Cristo.

A ressurreição é a chave de compreensão da cristologia para $W$. Kasper. É a consagração da pessoa de Jesus e sua causa. Sua análise da ressurreição

\footnotetext{
${ }^{21}$ Cf. Ibid., p.196.

${ }^{22}$ Cf. Ibid., p.196.
} 
de Jesus consegue mostrar que ela foi cumprimento do Antigo Testamento, da vida e obra de Jesus e que a confissão pós pascal anunciou na vida de Jesus a vinda do Reino de amor de Deus. Em sua análise se manteve fiel à sua concepção de que a cristologia atual deve ser orientada historicamente e assumir seu alcance universal e soteriológico. A perspectiva histórica estabelece um critério objetivo anterior ao querigma, e afasta a possibilidade de considerações mitológicas e ideologias modernas. O alcance universal liga questões fundamentais da humanidade com a causa de Jesus: o Reino de Deus. Jesus Ressuscitado torna-se o Espírito que dá a vida. Ele conduz a realidade para a sua meta escatológica.

\section{Referências Bibliográficas}

KASPER, W. Jesus, El Cristo. Salamanca: Ediciones Sigueme, 1986.

CONCÍLIO ECUMÊNICO DO VATICANO II. Constituição Pastoral sobre a Igreja no mundo de hoje, Gaudium et Spes. In: KLOPPENBURG, B; VIER F. Compêndio do Vaticano II. Petrópolis: Vozes, 1998.

Angela Cristina Germine Pinto Caldeira Doutoranda do Programa de Pós-graduação em Teologia da PUC-Rio, Brasil E-mail: angelacristinagpc@hotmail.com

Recebido em 01/06/13

Aprovado em 28/10/13 